\title{
ESTRATÉGIAS POSSÍVEIS PARA ENFRENTAR OS FASCISMOS LATENTES
}

\author{
Laisa Blancy de Oliveira Guarienti ${ }^{1}$
}

\begin{abstract}
Resumo: Com a figura de um guarda-chuva, imagem singela, tece-se a escrita de um texto que procura nas sutilezas das coisas simples, encontrar potências para a resistência. Eis que surge também um personagem que leva a escrita para a crença de que é possível sim, através de pequenas ações, hipergestos e extervenções exercer micropolíticas que denunciam as macro-extratificações e assim, um combate ativo se fez (por Jonas Hanway) e se faz (por mim, por você, por qualquer um) contrários aos fascismos impostos. Os conceitos de resistência e combate são tecidos pelo filósofo francês Gilles Deleuze (1997) e nos propulsionam a pensar ações insurgentes às mazelas atuais, assim como, na sequência final do texto, onde campos de possibilidades são abertos com estudos e grupos de pesquisas que já vêm realizando tais feitos.
\end{abstract}

Palavras-chave: combate; resistências; fascismo; hipergestos; extervenções.

\section{POSSIBLE STRATEGIES TO FACE LATENTE FASCISMS}

\begin{abstract}
With the figure of an umbrella, a simple image, the writing of a text is woven that seeks in the subtleties of simple things to find powers for resistance. There is also a character who takes writing to the belief that it is possible, through small actions, hypergestos and exterventions to exercise micropolitics that denounce macro-extratifications and thus, an active combat was made (by Jonas Hanway) and does (for me, for you, for anyone) contrary to the imposed fascisms. The concepts of resistance and combat are woven by the French philosopher Gilles Deleuze (1997) and propel us to think of insurgent actions to the current problems, as well as, in the final sequence of the text, where fields of possibilities are opened with studies and research groups that have already see doing such things.
\end{abstract}

Keywords: combat; resistances; fascism; hypergests; exterventions.

\section{Guarda-chuva}

Um guarda-chuva é a imagem que conecta a problemática principal do texto, é com esse exercício imagético que os conceitos deambularão pelos escritos a seguir. O guarda-chuva, objeto que ao longo da história passou por transformações em termos de usos como, proteger a cabeça dos reis e religiosos, o que levou o objeto a

1 Doutora pela Universidade Estadual de Campinas (UNICAMP) trabalha como Orientadora Educacional - Sesi / Santa Maria. Endereço: Av. Presidente Vargas, 1263/301, Centro. CEP: 97015511. Santa Maria/Rio Grande do Sul. E-mail: batupre@gmail.com 
ser direcionado a cultos e outras cerimonias litúrgicas, posteriormente passou a ser usado como acessório exclusivo feminino, e vemos com ele também, transformações em termos de modelos, estilos, cores, tamanhos, tecidos, etc. O guarda-chuva também tem por sua variação o nome de sombrinha ou guarda-sol e tem na sua origem a função de proteção contra o sol, visto que suas primeiras aparições se deram na antiga Mesopotâmia, atual Iraque, onde raramente chovia.

Avançando os séculos, temos como proliferação do uso do guarda-chuva e da sombrinha, que ainda no século XVIII era exclusivo das mulheres, uma quebra no fluxo. Jonas Hanway, que era um comerciante, viajante e escritor inglês, começou a aderir o uso do guarda-chuva contrariando a tendência da época (exclusivo às mulheres). Em decorrência dessa ação, durante sua vida foi alvo de ridicularização por parte da sociedade e somente após a sua morte o acessório se tornou então, de uso cotidiano para os homens. Além de, nestes mesmos meados de século, com a transformação do guarda-chuva para tecidos mais leves, como a seda, ele passou a ser usado também para os dias de chuva, que eram constantes na Inglaterra e demais regiões da Europa.

Pensemos em Jonas Hanway para iniciar as estratégias de combate ao fascismo. Fascismo este que se revela através de todas as formas de poder e que não tolera o nascimento de novas formas de vida, que depredam intensidades não formatadas em prol de um fluxo de vida lobotomizada. Jonas pela primeira vez rompeu com convenções corpóreas e modos de conduta. Rompeu com exclusividades e transgrediu papéis estagnados, num simples gesto de andar pelas ruas de Londres do século XVIII com guarda-chuvas. Foi assim que Jonas acabou incitando um jogo de atenções para aqueles que passavam em seu entorno. Ocasionando tensões e produção de discursos, gestos, olhares, boatos fascistas vindouros dos moralistas de sua época.

O uso do guarda-chuva para proteção contra a chuva, foi disseminado por entre homens a partir do final do século XVIII, assim como, o guarda-sol, ou sombrinha, exclusivo às mulheres, o guarda-chuva passou a quase compor obrigatoriedade no figurino da época, pois este acessório denotava status de nobreza. Ambos os utensílios eram e são usados para a proteção de algo vindouro do exterior, do fora (sol e chuva). 
No contexto da vida de um brasileiro, seja homem, mulher ou criança, usamos como acessório de uso cotidiano a sombrinha e o guarda-chuva, tanto para a proteção do sol quanto da chuva e como amparador para ambos os fenômenos da natureza. São eles que nos acompanham nas jornadas diárias, e foram com eles que nos ocupamos de reinventar proposições ao seu uso (intervenções artísticas, decoração, etc.). Jonas o fez muito bem em sua época, se expondo e criando nossas configurações rotineiras ao ser homem e andar de guarda-chuva. Mas e hoje? Como se "expor" com um guarda-chuva e sombrinha se seu uso é tão banal? Como a imagem do guarda-chuva e sombrinha podem fornecer ferramentas para o combate de um fascismo latente? Como romper com a sua lógica usual de proteção?

O guarda-chuva, elemento que se conecta aos corpos nos dias chuvosos e de sol, é usado como instrumento de proteção e desvio contra a chuva e o sol de todas as formas que nos afetam. Mas o que pode nos afetar para além da metáfora usada até então? Quem são os protegidos pensando em termos políticos no nosso atual governo que opera por um fascismo inflamado e descarado? Quem são aqueles com exclusividade, protegidos, que conseguem desviar a atenção, desviar dinheiro, desviar injúrias, desviar sentenças dos olhos dos não protegidos?

Então, para seguir nessa linha de raciocínio, se o guarda-chuva é aquilo que protege (mas protege quem de quem?) nossa outra imagem, para conversar com a primeira (guarda-chuva e sombrinha), é a chuva e o sol, eles que são vistos como os invasores que fazem "certos alguéns" descodificar modos estáticos de agir. São vistos como desordeiros e caóticos que querem desestabilizar e romper fluxos estagnados, são eles a fonte de toda a criação. O banqueiro, certamente se protege do endividado e com isso acaba lucrando em nome do Capital; o político se protege por detrás de um juiz que por sua vez também é protegido em nome da Lei; o abusador tenta desviar das acusações em nome de Deus; um aluno desvia do erro; o são da doença; mas também um rico tenta desviar do pobre; a esquerda da direita e assim por diante.

Corpos codificados desviam de serem afetados pelos invasores caóticos que querem produzir movimentos de multiplicidade. O múltiplo afeta negativamente o que quer homogeneizar, a diferença produz vertigem ao acomodado. O guarda-chuva e sombrinha então são os elementos que protegem vidas das transgressões, das ousadias, das tentativas, dos experimentos, da ação. É a chuva e o sol que criam 
significados e sentidos seja para a vida de um animal, vegetal, flor, mulher, criança, feiticeira.

Muitas vezes ao proteger nos tornamos ilesos às passagens da multiplicidade, e por isso mesmo, cegos à potencialidade em combater o intolerável. Ao desviar de uma escolha, quantas outras deixamos de eleger? Ao se proteger e desviar da chuva ou sol quantas outras possibilidades são encerradas num único modo de agir? A postura que o guarda-chuva nos impõe, proteção, modela corporeidades como uma das únicas imagens possíveis de defesa contra os fascismos a que somos sujeitados. $\mathrm{O}$ aluno se protege, mas a professora também, a diretora e assim por diante; o machista se protege e a mulher também.

A imagem do guarda-chuva, então, nos estabiliza numa comodidade em pensar numa única estratégia de resistência frente às modulações que se impõem. A proteção quase sempre vinculada em nome de Deus, da Lei, da moral, do capital, não acolhe as singularidades de cada acontecimento vivido.

\section{Pipocar micro inovações}

No rol das medidas protetivas que tentam privar vidas à expansão de experimentações possíveis (rupturas do "eu", ideias comuns, status quo, etc.), nos abstemos de "pipocar micro inovações ${ }^{2 "}$. O banqueiro se protege daquele endividado e desvia de sua atuação política e social roubando-o cada vez mais com sequências infinitas de empréstimos atrás de empréstimos e não inventa nada além disso. 0 banqueiro nesse caso, não fornece ferramentas para combater o fascismo, pelo contrário, ele cada vez mais produz diferença, ganância e ódio. Mas, por outro lado, é o endividado aquele que ainda pode se abrir para o sol e a chuva, e é ele que detém as forças do combate, e é somente ele que ainda é capaz de produzir movimentos aberrantes e combatentes.

Não será o abusador que criará esses movimentos, mas sim a vítima que pode produzir outros subterfúgios construindo um fluxo que, além de desviar do abusador, desvia da Lei, mesmo que a utilizando e ainda assim, cria suas estratégias de combate

\footnotetext{
2 Texto "Repensar abstrações" de Luiz Orlandi, apresentado no VII Seminário Conexões: Deleuze e Cosmopolíticas e Ecologias Radicais e Nova Terra e... na Unicamp em 2017 e ainda no prelo.
} 
ao fascismo. Foi Jonas, o comerciante que se expôs ao enfrentar uma sociedade hierarquizada e moralizante, foi ele que trouxe "um pipocar de micro inovações" num século XVIII. A força do combate veio do povo, dos desprotegidos, dos que correm riscos e que se queimam com o sol e se molham com a chuva; essa força não vem dos protegidos.

No Brasil, somos constituídos por uma herança de mentalidade escravocrata. O banqueiro que pensa que pode humilhar o endividado, o professor que pensa que pode perseguir um aluno, um Estado que pensa que pode controlar vidas, o machista que pensa que pode domar uma mulher. Há sempre um "que" em querer abafar as potencialidades alheias e em escravizar a vitalidade. Quando Gilles Deleuze (1997) nos convida a combater, prioritariamente, é sempre o nazista disposto a emergir das nossas próprias entranhas, "fico pensando que nosso nazista pré-Hitler está na presunçosa mente escravocrata que herdamos fatalmente de uma história não ainda eticamente transformada em vastas multiplicidades de bons afetos" (ORLANDI, 2017, $\mathrm{s} / \mathrm{p})$.

É desse modo que começamos a retomar a pergunta relativa a uma das problemáticas aí embutidas, a problemática de mentes escravocratas propensas a apoiar e praticar atrocidades ou, no mínimo, a gerar sofrimentos, tristezas, amortecimentos da vontade alheia de viver.

Trata-se de uma das primeiras e constantes operações do espírito filosófico, do espírito científico, do espírito artístico, mas também do espírito dos que odeiam ou amam isto ou aquilo, dos que avaliam criteriosamente o valor deste ou daquele metal e também dos que quase se perdem em vagas contemplações de paisagens. A operação a que me refiro é a da abstração (ORLANDI, 2017, s/p).

Imaginemos Jonas que, descuidado, escolha a vereda que o levará ao alcance de homens machistas de qualquer beco londrino: ele precisa selecionar detalhes de micro atenções para sair ileso de tal emboscada, que acarretará um bom andamento de sua existência. É possível polemizar isso, dizendo, por exemplo: as abstrações, as seleções abstrativas que a gente faz ao longo de um percurso dependem daquilo que, previamente, se quer. Nesse sentido, Jonas diria: quero usar um guarda-chuva, portanto pegarei o caminho que, mesmo ao léu, acabará me levando aos homens da moral. 
O que Jonas está esquecendo é que seu prévio querer usar um guarda-chuva já é uma abstração. Esse um Jonas provavelmente não está fazendo a pergunta nietzschiana: quem, em mim, está querendo usar um guarda-chuva e assim desestabilizar percepções em seu entorno? É essa a pergunta que a mente escravocrata pode fazer a si própria, ganhando, assim, a possibilidade de confrontarse com o inquilino nazista que o habita: quem, em mim, vive querendo piorar as vidas? Quem, em mim, está se deliciando ou se prejudicando com tal ou qual abstração? Quem, em mim, está protegido, ou não, com tal ou qual abstração?

Essas considerações são uma espécie de introdução à necessidade de pensarmos as operações de abstração num quadro de mais concreta dramaticidade. Conforme a abstração que se faça, mudam-se as consequências práticas e teóricas em todos os campos. Qual é a principal abstração que praticamos como herdeiros contaminados pela duradoura mente escravocrata? Por que essa mentalidade pratica com tanta facilidade a abstração da humanidade alheia?

A mente escravocrata nunca deixará de se sentir cinicamente à vontade, enquanto pratica suas abstrações no Brasil, enquanto suas próprias vítimas continuarem a fazer abstração da possibilidade do seu próprio poder coletivo de impor respeito. Essa ética pede, portanto, ação coletiva, união de forças. Ou melhor, ela só emerge quando cada vítima se sente forçada a ver numa outra vítima uma força de resposta que ela não vê em si mesma. A força coletiva emerge quando há uma quebradeira de abstrações paralisantes (ORLANDI, 2017, s/p).

Um combate aos fascismos seria então o afastamento daquelas medidas que se dizem protetivas, e com a imagem do guarda-chuva e sombrinha que simbolicamente representam cada tipo de fascismo que tenta nos atingir, enfrentar e sentir toda força de uma chuva e de um sol que nos leva a não cair nas abstrações como a forte tendência a um julgamento cunhado na mentalidade escravocrata.

O juízo impede a chegada de qualquer novo modo de existência. Pois este se cria por suas próprias forças, isto é, pelas forças que sabe captar, e vale por si mesmo, na medida em que faz existir a nova combinação. Talvez esteja aí o segredo: fazer existir, não julgar. Se julgar é tão repugnante, não é porque tudo se equivale, mas ao contrário porque tudo o que vale só pode fazer-se e distinguir-se desafiando o juízo (DELEUZE, 1997, p.173).

Não mais nos privarmos de chuva e sol, mas sim nos permitir senti-los, com toda sua pungente força, como forma de conhecê-los e a partir daí, criarmos estratégias para minimizar seus efeitos sobre nossos corpos, sem esquecermo-nos da pergunta nietzschiana: quem em mim tende a tais ou quais inclinações éticas, 
políticas, estéticas e pedagógicas. Fazer essa pergunta com mais lucidez para resistirmos e enfrentarmos a pelo nu os fascismos que querem exterminar nossa vitalidade, inclusive aqueles em que nós mesmos carregamos.

Quando em sua potência é justo a chuva e o sol que necessitamos enfrentar, sem se proteger, como mecanismos de interação com o exterior, força necessária para nos despirmos e encarar cada gota e raio que cai sobre nossos corpos. Rasgar e mesmo abandonar o guarda-chuva, assumir uma posição de risco lúcido, sem abstrair inclinações. Não podemos deixar a humanidade ser sucateada pelo abstracionismo...

Jonas assume e afirma sua vontade em querer usar um guarda-chuva quando não se podia, sozinho não teve forças para enfrentar tamanho abstracionismo alheio, precisou morrer para que sua ideia vingasse, "padeceu pessoalmente e singularmente do juízo" (DELEUZE, 1997, p. 162). A vítima de estupro, de controle abusivo, homofobia, racismo deve encarar a chuva e o sol desprotegida daquilo que se diz segurança para todos e para o bem, porém, por outro lado, não deve tomar essa luta isoladamente. Encontrar pessoas, lugares, pensamentos que acolham e impulsionem o povo a ecoar suas mazelas e criar assim, novas "micro inovações", pois "há sempre um coletivo se está sozinho" (DELEUZE e GUATTARI, 1996, p. 23).

\section{Ações combatentes}

Tecendo experimentações possíveis de atos de resistências, eis que surgem intercessores para nos fortalecer e pensar em modos transgressores e potentes ao combate dos fascismos. Podemos pensar aqui em alguns conceitos teóricos como 0 de hipergestos e o de extervenções. Dois conceitos que nos possibilitam sentir que é possível fazer um coletivo explodir em gestos de insurreição frente aos constantes abalos que imperam nossas vidas. A seguir apresento brevemente a proposta de cada um dos conceitos para então, nos fortalecer e saber que não estamos isolados por esse mundo à fora.

A noção de hipergesto, termo criado pelo professor de filosofia da educação da Universidade de Milão-Bicocca (UNIMIB), Paolo Mottana em 2017, está para ser pensado e praticado como gestos multiplicadores de outros gestos, num ato 
demonstrativo de rupturas. Gestos transgressivos que não procuram danos, mas que acolhem os riscos vindouros sempre numa tentativa de minimizá-los. Praticar um hipergesto é agir de modo breve e a ação deve ser de fácil entendimento a todos aqueles que passam pelo caminho da ação, é quase uma ação performática, mas sua função principal não se preocupa com a estética e sim com os efeitos políticos.

Não é um ato passageiro, pois o sentido deve permanecer e atravessar as pessoas. Tocar um ponto nevrálgico de uma questão atual e assim, disseminar a ideia. O hipergesto deve denunciar qualquer coisa que impeça a proliferação das diferenças e afirmar as expansões dos processos de subjetivação. O seu efeito e impacto podem não ser momentâneos, mas serão perturbantes porque sua intenção é permanecer.

Outro fator de extrema importância na teoria de Mottana é a forma de disseminação do hipergesto. Então um dos grandes potenciais a que a teoria deve ser aliada são os meios de comunicação, fortemente introduzidos no cotidiano de qualquer família. Celulares com internet, blogs, computadores, televisores, enfim, uma gama de possibilidades a fazer esse hipergesto não ser vistos apenas por aqueles poucos transeuntes que passam pelas vias das cidades, mas disseminados na massa.

Somente um fluxo massivo de informação radicalmente outra a nível de massa pode mudar alguma coisa. E sobre esse caminho o hipergesto é um primeiro instrumento, não o único certamente, mas um dos cruciais, próximo daqueles que podem equipar uma outra via, porque sejamos conscientes de que sem um impacto forte sócio comunicativo não teremos hoje nenhuma forma de fuga. (MOTTANA, 2017, orelha do livro).

As ações realizadas por qualquer um de nós, diferente de James, pois aqui existe uma intencionalidade na ação, podem ser vistas como uma possibilidade de introdução na noção de hipergesto, pois o hipergesto é a "conexão de mais gestos, em uma concatenação que é determinada pela capacidade de exposição e influência (...). Hipergesto existe quando um gesto desperta outros gestos." (IDEM, p.18). Assim, as ações realizadas por cada um de nós podem provocar justamente esse contágio em outras pessoas a se envolverem com a proliferação de novas e outras ações.

Agir contra os afrontes que nos sufocam cotidianamente, mesmo que levando um guarda-chuva em punhos e com intenção, pode se tornar um meio de resistência, emitindo gestos de afronte aos parâmetros ditos padrões de uma sociedade que valoriza uma moral escravocrata. É assim que temos como tecido aliado, a cidade, e todas as possibilidades que ela oferece. Não é função do hipergesto, explicar as suas 
ações, pois elas ecoam com a intenção de serem propagadas através da afetação de outros corpos, num movimento propulsor de sensações e expressões a serem disseminadas num campo estético, ético, artístico e político.

Agora, sabemos bem, ou melhor, alguns de nós não mesmo o sabem, que
abaixo da crosta do disciplinamento sistemático do poder do imaginário
hegemônico e dos seus instrumentos de controle, ou, se preferirem, na
sempre mais sofisticada "economia" e política da "atenção" (CITTON, 2012),
existe, de modo mais ou menos pronunciado, um enxame de pequenos
contra movimentos, de contra condutas, um formigueiro latente e semilatente
de gestos de insubordinação, de práticas alternativas de vida. Então, é nesse
quadro de movimentos dispersos e de tensões, todavia difusa, de esperas
imperceptíveis, mas inequívocas, que um hipergesto "frontal" pode surgir num
potencial detonador de efeitos de transformação molares. (IDEM, p. 18).

Ao querer incluir a proposta dos hipergestos nas ações de insurreição ao combate ao fascismo, Mottana aponta que tal empenho é possível na medida em que "a reassunção a pleno título dos seus contributos na realidade cotidiana, podem proporcionar uma multiplicidade de hipergestos como novas práticas de convivência, de tempo, de espaço e de fluxo dos corpos." (IDEM, p.40). Não mais sujeitos desapropriados da potencialidade em se exprimir pelas cidades, mas sim, sermos atores inseridos no contexto social, e de legitimar todas as formas de expressão como formas de acusar o intolerável.

Pois, se seguirmos a linha de pensamento do autor, nos seus estudos sobre os combates ao intolerável, não se trata de alistar um novo exército de reprodutores, mas o contrário disso, os hipergestos contagiam sujeitos que experimentam, exploram, observam, participam e depois ainda, aprofundam e criticam não só equiparados com velhos argumentos cimentados pela hipócrita moral, mas com sede em descobrir portais, campos de afetação, tocas, que possam ser habitadas como uma potência de combate aos fascismos.

Outra perspectiva de ação é vista pela cidade de Belo Horizonte/MG. Mais perto do nosso contexto, podemos enxergar práticas que acontecem com o Grupo de Pesquisas grupelho ${ }^{3}$. Grupelho ${ }^{4}$ é um grupo de estudos e ações em filosofia e

\footnotetext{
3 https://ufmggrupelho.wixsite.com/grupelho

${ }^{4}$ Do francês, groupuscules pode ser traduzido por grupúsculos, como o fez Roberto Machado, mas também por grupelhos, como encontramos na tradução de Suely Rolnik em "Somos todos grupelhos" (GUATTARI, 1981, p. 18). E foi exatamente daí que tiramos o nome de nosso grupo e o escrevemos com letra minúscula inicial, invariavelmente. No uso comum, a palavra grupelho carrega em si um sentido pejorativo. No entanto, o uso que fazemos dela é afirmação de posição política e filosófica. No sentido político, o uso dessa palavra - grupelho - se refere aos pequenos grupos dissidentes do Partido
} 
educação da UFMG. Situado nos espaços entre filosofia, educação e arte, o grupo deseja produzir conhecimentos a partir das experimentações do pensamento, na sua multiplicidade. Trata-se de pensar com o corpo, na rua.

Pensar diante da cidade, com a gente, que passa. Pensar é criar e esta criação é livre. Livrar-se do senso comum, livrar-se das formas preconcebidas de pensar, livrar-se das essências, dos métodos, dos universais, etc... Essa criação do pensamento como experimentação, é impulsionada por problemas, problemas que se impõem e obrigam o pensar a se mover.

O grupelho tem por intenção, mover corpos e sair às ruas, com a necessidade de inventar formas de restituir uma intensa relação entre filosofia e vida, o grupo está imerso na crença de que não há nenhum sentido na filosofia se ela não for vivida, se não for incorporada. É a busca da filosofia tornada gesto. Como mexer o corpo para que ele faça o pensamento se mover? Como mover nossos corpos, na rua, para que sejam vistos e possam afetar os transeuntes apressados da cidade? Como praticar filosofia perante os outros, de forma que os afete? Mais do que da filosofia em si, tratase, talvez, do pensamento, do pensar. Como pensar de outros modos? Pensar sem a cabeça. Sair na rua, meio à deriva, tateando, fazendo experimentações e insuflar pequenos tropeções, gagueira, foco-desfoco, acontecimento.

Essas ações filosóficas experimentadas na rua, o grupelho nomina de extervenções. Não são intervenções, porque o grupo pensa que uma intervenção pressupõe um todo significativo no qual se pretende interferir para mudar algo ali, muitas vezes já intencionando a direção e o teor da mudança. Uma extervenção, por outro lado, está intensamente calcada na ideia de rizoma, a cidade é um rizoma, o pensar é um rizoma, também o aprender. Rizoma é sistema a-centrado que muda de natureza a cada nova conexão. É um sistema aberto, que tem inumeráveis e imprevisíveis entradas. Vai-se para as ruas dispostos a (quase) qualquer coisa, não se sabe o que pode acontecer.

Comunista, que, na década dos anos 1970 se configuraram como movimento intelectual de oposição ao sistema comunista. "'Dissidentes' corresponde à palavra russa inakomysliachtchie, 'os que pensam de outra maneira"' (FOUCAULT, 2008, p. 294). E no sentido "ontológico", grupelho, grupo menor, atualiza a ideia de que toda subjetividade é, de certa forma, grupal, uma multiplicidade singular, em movimento, composta mais por acontecimentos do que por substâncias. 
Ao contrário das intervenções urbanas/performances o grupelho chama as suas ações de extervenções, exter-invenções, pois são ações que vêm do fora, querem trazer o fora, o caos, aquilo que ainda não foi pensado. Tem a ver com sair dos significados, por meio de encontros estéticos, do humor, da estranheza, para criar sentidos. Escapar dos significados que remetem ao mesmo e perseguir encontros, ocasionar fricções que podem gerar sentidos singulares. Dar o que pensar. Sair na rua e enxamear signos estranhos, extranhos, que incitem a decifração, que movam o pensar; um cutucão, um incentivo para que se saia do lugar do já sabido, das vivências cotidianas, para que se possa escapar, por pouco que seja, do percurso percorrido deste tipo de vida, na atualidade, que parece já ter sido vivido antes mesmo de começar; vida que perde sua força a cada reprodução do seu mesmo.

Inventam-se as extervenções pensando em sabotar as engrenagens do pensamento automático, do pensamento disciplinado, modulado, o pensamento do mesmo. Isto já não é mais pensamento, pois pensar implica necessariamente em criação, pensar é criar, sempre, porque é justamente a ação de lidar com aquilo que ainda não se sabe, o que ainda não foi composto em significados, ainda não se atualizou e é passível dessa ação para vir a ser algo, este que será, portanto, sempre novo. Nas extervenções, trata-se de enxamear signos que afetem, que atravessem como flechas, que fisguem o interesse e ponham o pensamento em movimento ${ }^{5}$.

E é com essa força pungente que ambos os conceitos, hipergestos de Paolo Mottana e extervenções do grupelho, mas também qualquer um como Jonas, podem fornecem pistas de ações possíveis a serem realizadas no cotidiano das nossas realidades. Combate aos fascismos com o corpo, com objetos simples, na rua e principalmente com projeção para que pessoas alheias a isso tudo, possam enfim, também serem atingidos por essa verve que pulsa no espírito daqueles insurgentes e sedentos por uma vida não fascista.

\footnotetext{
5 Todo o percurso descrito a respeito do grupelho foi retirado do livro de Renata Aspis "PERCURSOS DE UMA PESQUISA - Fazer filosofia com o corpo na rua: experimentações em resistência" que ainda está no prelo.
} 


\section{Conclusão}

Figura 1: Sobrevoar linhas de fugas...

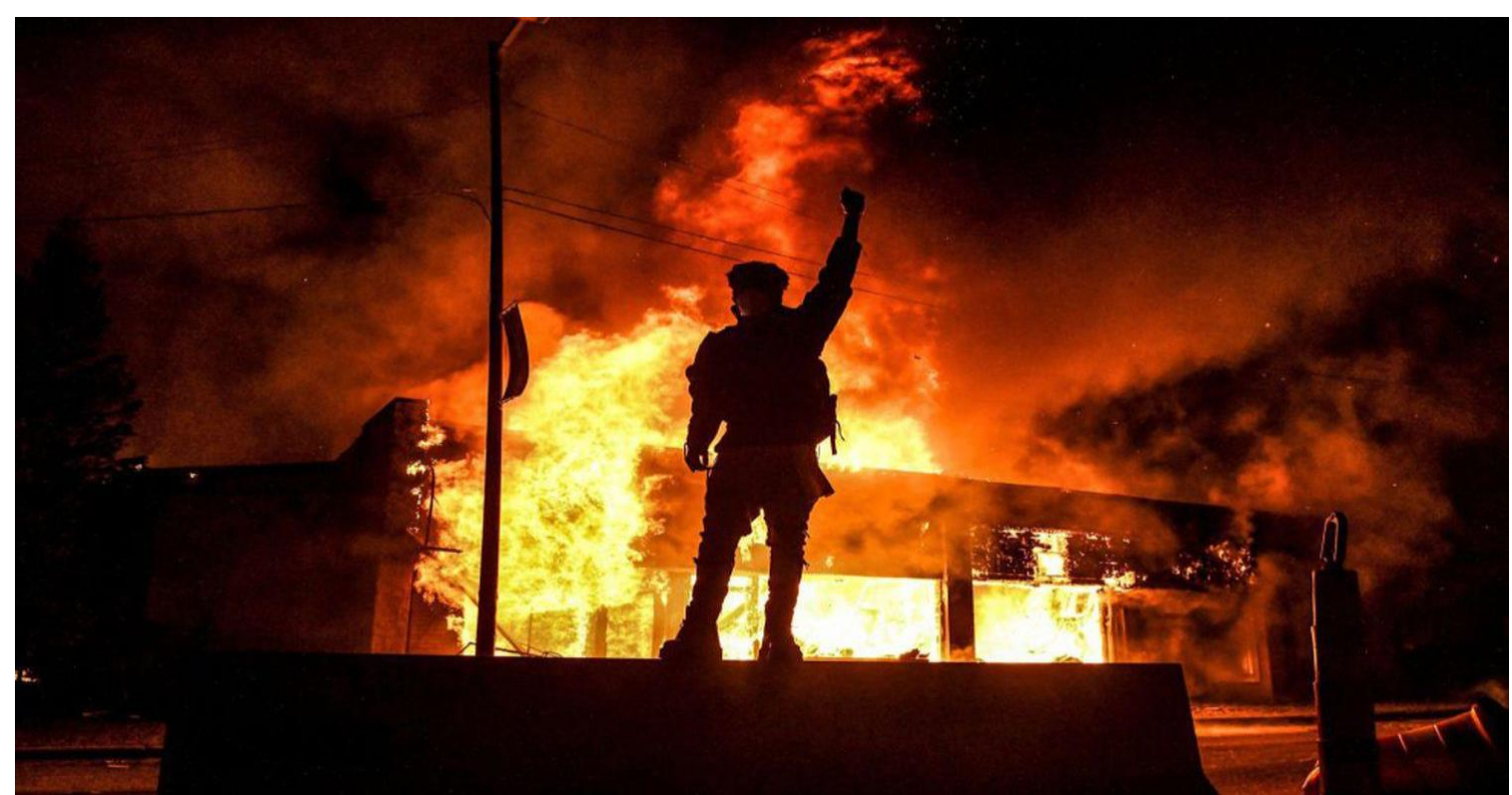

Fonte: Créditos de CHANDAN KHANNA / AFP (JORNAL EL PAIS - INTERNACIONAL). IMAGEM: https://brasil.elpais.com/internacional/2020-05-30/revolta-pela-morte-de-george-floyd-se-apodera-deminneapolis-coringa-anda-solto-pelas-ruas.html Acesso em: junho/2020.

\section{Referências}

DELEUZE, Gilles. Crítica e Clínica. Tradução Peter Pál Pelbart. São Paulo: editora 34, 1997.

DELEUZE, Gilles; GUATTARI, Félix. Mil Platôs: capitalismo e esquizofrenia, v. 3. Tradução Aurélio Guerra Neto, Ana Lúcia de Oliveira. Lúcia Cláudia Leão e Suelly Rolnik. São Paulo: Editora 34, 1996.

MOTTANA, Paolo. L'Ipergesto: disseminare utopia. Milano: Asterios, 2017. 